\title{
GCU
}

Glasgow Caledonian

University

University for the Common Good

\section{Power frequency interference and suppression in measurement of power transmission tower grounding resistance}

Wenjun, Zhou; Yushun, Liu; Li, Gongxin; Yan, Guozhi; Yang, Shuai; Li, Han; Zhou, Chengke; Su, Charles Qi

Published in:

IEEE Transactions on Power Delivery

DOI:

10.1109/TPWRD.2014.2370037

Publication date:

2014

Document Version

Author accepted manuscript

Link to publication in ResearchOnline

Citation for published version (Harvard):

Wenjun, Z, Yushun, L, Li, G, Yan, G, Yang, S, Li, H, Zhou, C \& Su, CQ 2014, 'Power frequency interference and suppression in measurement of power transmission tower grounding resistance', IEEE Transactions on Power Delivery, vol. 30, no. 2, pp. 1016-1023. https://doi.org/10.1109/TPWRD.2014.2370037

\section{General rights}

Copyright and moral rights for the publications made accessible in the public portal are retained by the authors and/or other copyright owners and it is a condition of accessing publications that users recognise and abide by the legal requirements associated with these rights.

Take down policy

If you believe that this document breaches copyright please view our takedown policy at https://edshare.gcu.ac.uk/id/eprint/5179 for details of how to contact us. 


\title{
Power Frequency Interference and Suppression in Measurement of Power Transmission Tower Grounding Resistance
}

\author{
Wenjun Zhou, Senior Member, IEEE, \\ Yushun Liu, Gongxin Li, Guozhi Yan, Shuai Yang, Han Li, Chengke Zhou, Senior Member, IEEE, and \\ Charles Qi Su, Senior Member, IEEE
}

\begin{abstract}
Due to the electromagnetic induction between transmission lines and the associated grounding wires, power frequency current causes flow into the ground network via the metallic tower, which may interfere with grounding resistance measurements. This paper analyzes the mechanisms of this interference, and shows that power frequency interference becomes stronger at phase-wire transposition towers. Grounding resistance measurement by the variable frequency (VF) method has been proven to be effective in dealing with power frequency interference. However, the test equipment based on the VF method is always deactivated when the external interference voltage exceeds a preset level in order to avoid false readings. This paper aims at tackling the problem by introducing a reverse phase cancellation (RPC) method, which acquires and processes the interference signal before generating a cancelling signal with the same amplitude and frequency and a phase which is exactly opposite in polarity. This paper proves that the RPC method represents an excellent improvement over the VF method since it retains the advantages of $\mathrm{VF}$ and avoids the trip-out of test equipment due to excessive interference.
\end{abstract}

Index Terms-Grounding resistance measurement, power frequency interference, reverse phase cancellation method, transmission tower, variable frequency method.

\section{INTRODUCTION}

$\mathbf{T}$ HE GROUNDING resistance of a transmission tower is an important parameter in lightning protection [1], [2], because it affects lightning overvoltages [3], [4]. It is therefore necessary to measure the grounding resistance annually to determine if it is within an acceptable level [5].

When applying the fall-of-potential (FoP) method [6], [7] to measure the grounding resistance, test equipment is often employed, which is connected to the grounding network by a test

Manuscript received December 31, 2013; revised July 07, 2014 and August 20, 2014; accepted November 06, 2014. Date of publication November 25 , 2014; date of current version March 20, 2015. This work was supported by the Natural Science Foundation of China (51277136). Paper no. TPWRD-014772013.

W. Zhou, Y. Liu, G. Yan, S. Yang, and H. Li are with the School of Electrical Engineering, Wuhan University, Wuhan 430072, China (e-mail: ys3254@163. com).

G. Li is with Fujian Electric Power Co. Ltd., Fuzhou 350000, China.

C. Zhou is with the School of Engineering and Built Environment, Glasgow Caledonian University, Glasgow G4 0BA, U.K.

C. Q. Su is with School of Nanyang Campus, Singapore 569823.

Color versions of one or more of the figures in this paper are available online at http://ieeexplore.ieee.org.

Digital Object Identifier 10.1109/TPWRD.2014.2370037 wire for injecting power frequency current, and two wires connected to grounding electrodes for collecting return current and measuring the voltage drop. With the ratio of the return current and voltage drop, the grounding resistance can be determined [8]-[11]. However, the FoP method is vulnerable to interference due to the voltage induced in the test object. This is due to mutual inductance between the grounding wires on top of the transmission tower and the high-voltage (HV) transmission lines. The VF method uses the Fourier transformation to analyze the spectrum of the interference signal and then selects a frequency which is not interfered with for testing. However, in order not to provide false readings, the test equipment is always deactivated when the external interference voltage exceeds a preset level, meaning that this method cannot be relied upon when interference is strong.

This paper analyzes the source and mechanism of power frequency interference during measurement of transmission tower grounding resistance, and proposes a reverse phase cancellation (RPC) method as a means of eliminating this interference.

\section{Analysis of the Mechanism of the Power FREQUENCY INTERFERENCE}

\section{A. Analysis of the Interference Current}

From frequency spectrum analysis carried out by the authors, the main interference during grounding resistance measurement was found to be power frequency interference. This agrees with earlier observations [12].

In order to protect transmission lines from lightning, a highvoltage transmission-line system ( $220 \mathrm{kV}$ or above) in a lightning area is required to have two grounding wires [13], which are physically positioned above the three-phase lines.

Due to the mutual inductance between the overhead transmission lines and the grounding wires, current is induced in each of the grounding wires and flows to ground via the transmission tower and the grounding network [14]-[17]. This power frequency current disturbs the measurement.

Because of the mutual inductance between the grounding wire and the transmission lines, any imbalance in load current among the three phases would cause a current to flow in the closed loops formed by the grounding wires and the ground between towers, as shown in Fig. 1.

The equivalent circuit model is given in Fig. 2. $Z_{n, 1}$ and $Z_{n, 2}$ are the self-inductances of the two grounding wires, and 


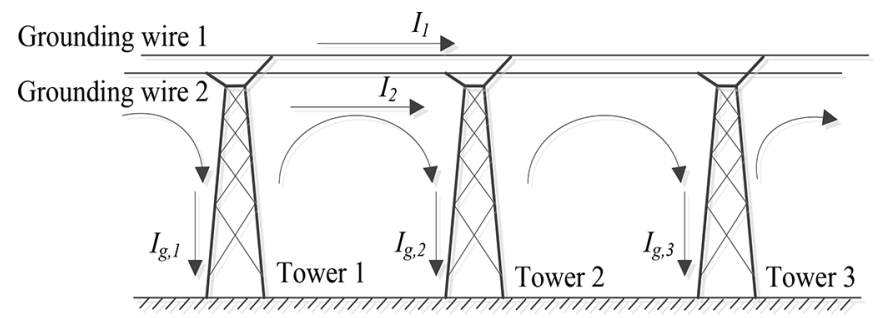

Fig. 1. Principle of interference current flowing in a power transmission system.
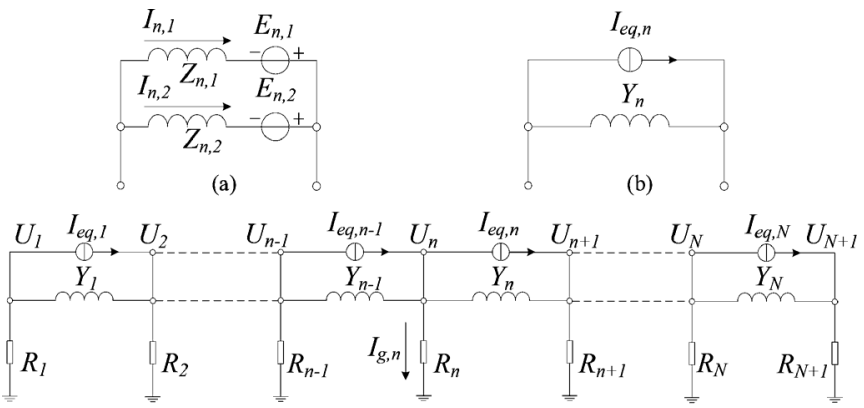

(c)

Fig. 2. Equivalent circuit representing the flow of interference current: (a) representation of the grounding wire between two towers, (b) the Norton equivalent circuits of (a), and (c) the nodal model for representing the inductance of the power lines.

$E_{n, 1}$ and $E_{n, 2}$ are the induced electromotive forces on these grounding wires. The values of $E_{n, 1}$ and $E_{n, 2}$ depend on the detailed design of a tower. The factors include the physical size of the tower, the distances between conductors, and the way conductors are transposed.

A circuit model of the grounding wires between towers is illustrated in Fig. 2(a). For simplicity, the loop current method is used to solve the equations. Fig. 2(b) shows the Norton equivalent circuits. Formulas (1) and (2) provide the admittances of the equivalent circuit and the equivalent source

$$
\begin{aligned}
Y_{\mathrm{n}} & =\frac{Z_{n, 1}+Z_{n, 2}}{Z_{n, 1} Z_{n, 2}} \\
I_{\mathrm{eq}, n} & =\frac{E_{n, 2} Z_{n, 1}+E_{n, 1} Z_{n, 2}}{Z_{n, 1} Z_{n, 2}} .
\end{aligned}
$$

Based on the simplified model in Fig. 2(b), a simplified overhead ground line model can be deduced as Fig. 2(c). The nodal method can be applied to solve $U_{n}$ from the equivalent circuit. Formulae (3)-(5), as shown at the bottom of the next page, are the voltage calculation equations of different nodes. Formulas (6)-(10), shown at the bottom of the next page, are the equations for analysis of the interference current in a transmission-line system deduced from (3)-(5). Equation (12) gives the node current flowing into the ground from the tower, as shown at the bottom of the next page.

Depending on the transposition arrangement of the transmission lines, elements in the transposition coefficient matrix [K], as shown in (9), take different values. Their absolute values are equal to one when conductors are not transposed and are always greater than one when conductors are transposed [18]-[20]. From (11) and (12), it is obvious that current flowing from the tower to ground is greater when conductors are transposed.

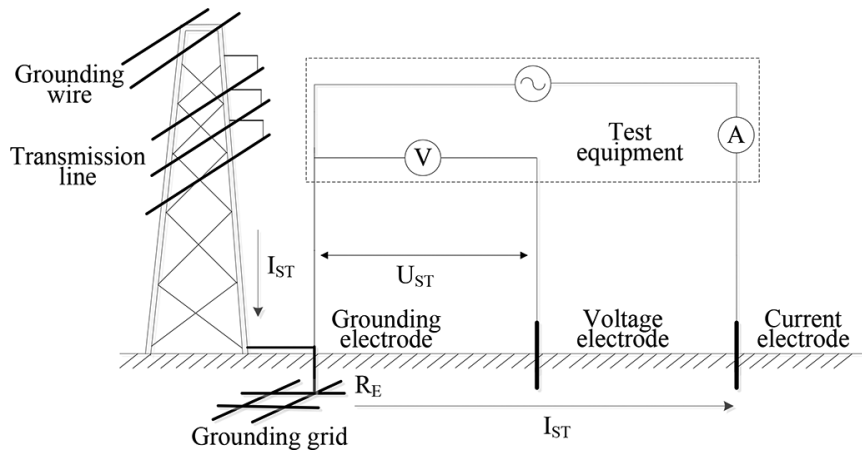

Fig. 3. Schematic diagram of the grounding resistance test using the FoP method.

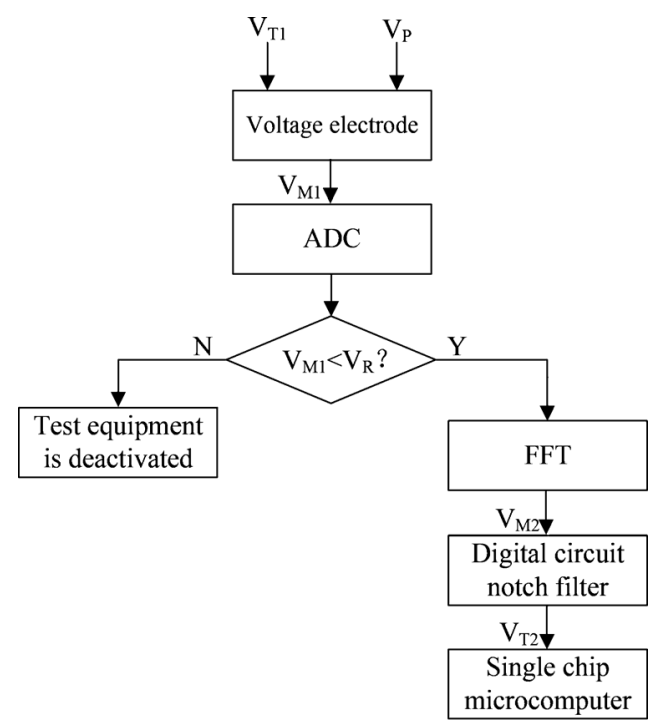

Fig. 4. Block diagram of the VF method.

\section{B. Soil Resistivity}

Fig. 3 shows a schematic diagram of how the VF method is applied to measure grounding resistance, where the measurable power frequency interference voltage $\mathrm{U}_{\mathrm{ST}}=\mathrm{I}_{\mathrm{ST}} \cdot \mathrm{R}_{\mathrm{E}} \cdot \mathrm{I}_{\mathrm{ST}}$ is the current flowing into the ground, and $\mathrm{R}_{\mathrm{E}}$ is the grounding resistance. From Ohm's law, the greater value of the grounding resistance, the greater value of $\mathrm{U}_{\mathrm{ST}}$. Commonly found in mountainous areas, the grounding resistance of a transmission tower is greater than $10 \Omega$ [21].

In summary, a high level of current flowing into the ground and great grounding resistance are the main reasons for strong power frequency interference. This paper proposes a new method of measuring low-frequency tower footing resistance on in-service transmission lines.

\section{Mechanism of Excessive Power Frequency INTERFERING WITH THE VF METHOD}

When test equipment employing the VF method is applied, a current square wave of variable frequency is injected into the grounding network [22], [23]. The acquired analog signal is first converted into digital signal through the analog-to-digital converter (ADC) before being converted into the frequency domain by fast Fourier transformation (FFT). A digital notch filter is then applied to remove the power frequency interference. Finally, the value of grounding resistance is calculated. The schematic diagram of the VF method is shown in Fig. 4. 
Fig. 4 illustrates the flowchart of the VF method, where $V_{T 1}$ (analog signal) is the variable frequency voltage generated by the equipment for measurement of the grounding resistance; $\mathrm{V}_{\mathrm{P}}$ (analog signal) is the power frequency interference voltage which is inherent in the power network; $\mathrm{V}_{\mathrm{M} 1}$ (analog signal) is the sum of $\mathrm{V}_{\mathrm{T} 1}$; and $\mathrm{V}_{\mathrm{P}} ; \mathrm{V}_{\mathrm{R}}$ is the ceiling value for the signal voltage, above which the equipment ceases to function; $V_{\mathrm{M} 2}$ (digital signal) is the voltage signal $\left(\mathrm{V}_{\mathrm{M} 1}\right)$ in frequency domain; and $\mathrm{V}_{\mathrm{T} 2}$ (digital signal) is the variable frequency testing voltage in the frequency domain following the removal of power frequency interference.

Disconnection of the equipment occurs when $\mathrm{V}_{\mathrm{M} 1}$ exceeds a threshold value in order to avoid false readings caused by heavy signal attenuation [24]. In the examples presented, the threshold value $V_{R}$ is fixed at $50 \mathrm{~V}$ and the measurement voltage $V_{T 1}$ is assumed to be $30 \mathrm{~V}$. Fig. 5(a) shows the case when the interference voltage is $10 \mathrm{~V}$. In this case, $\mathrm{V}_{\mathrm{M} 1}$ is equal to $40 \mathrm{~V}$, which is below the threshold voltage of $50 \mathrm{~V}$, and the results generated by the equipment reflect the real situation. When the interference voltage reaches $55 \mathrm{~V}, \mathrm{~V}_{\mathrm{M} 1}$ attains a level of $85 \mathrm{~V}$, thus exceeding the threshold value. As shown in Fig. 5(b), the equipment gives a reading below the true value due to attenuation within the analog circuitry.

Although the VF method is capable of alleviating the interference during the measurement of grounding resistance, it is not applicable when excessive power frequency interference is present. In China, more than $60 \%$ of HV transmission towers are located in mountainous areas, meaning that for a significant proportion of these $\mathrm{HV}$ transmission towers, their grounding resistance cannot be measured accurately by using either the FoP method or the VF method due to the reasons discussed before.

\section{Proposed RPC Method for Reducing Power FREQUENCY INTERFERENCE}

\section{A. Principle of RPC Method}

Fig. 6 shows the principle of the test equipment employing the proposed interference cancellation device, connected between the voltage electrode and the test equipment. This device generates a cancellation voltage signal which has the same amplitude and frequency as the interference voltage signal, but is of the opposite polarity. The output voltage signal cancels the power

$$
\begin{aligned}
& \left(Y_{1}+1 / R_{1}\right) U_{1}-Y_{1} U_{2}=-I_{\mathrm{eq}, 1} \\
& -Y_{n-1} U_{n-1}+\left(Y_{n-1}+Y_{n}+1 / R_{n}\right) U_{n}-Y_{n} U_{n+1}=I_{\mathrm{eq}, n-1}-I_{\mathrm{eq}, n} \\
& -Y_{N-1} U_{N-1}+\left(Y_{N}+\frac{1}{R_{N+1}}\right) U_{N+1}=I_{\mathrm{eq}, N} \\
& {[Y][U]=[K][I]}
\end{aligned}
$$

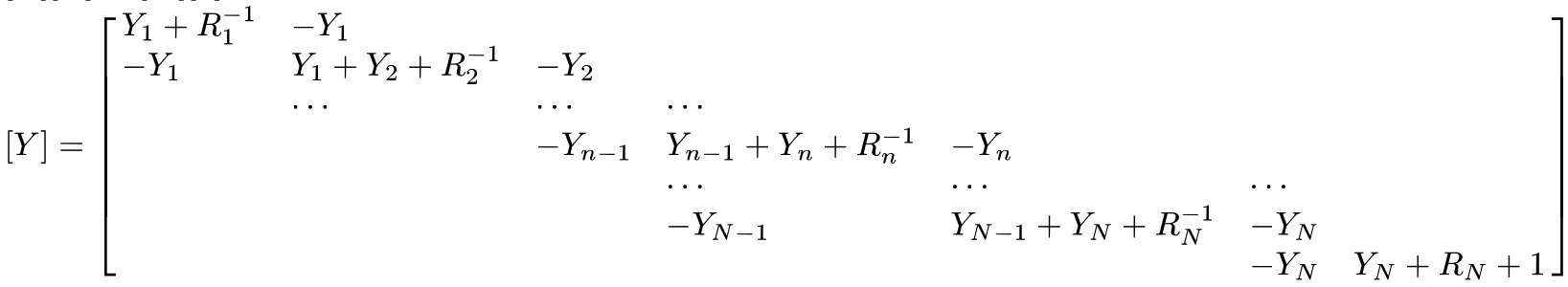

$$
\begin{aligned}
& {[U]=\left[\begin{array}{l}
U_{1} \\
U_{2} \\
\vdots \\
U_{N+1}
\end{array}\right]} \\
& {[K]=\left[\begin{array}{ccccc}
-1 & & & \\
& -1 & & \\
& 1 & -1 & \\
& & \ddots & \ddots & \\
& & & 1 & -1 \\
& & & & 1
\end{array}\right]} \\
& {[I]=\left[\begin{array}{l}
I_{\mathrm{eq}, 1} \\
I_{\mathrm{eq}, 2} \\
\vdots \\
I_{\mathrm{eq}, N} \\
I_{\mathrm{eq}, N+1}
\end{array}\right]} \\
& {[U]=[K][I][Y]^{-1}=[K][I][Z]} \\
& I_{g, n}=U_{n} / R_{n}
\end{aligned}
$$




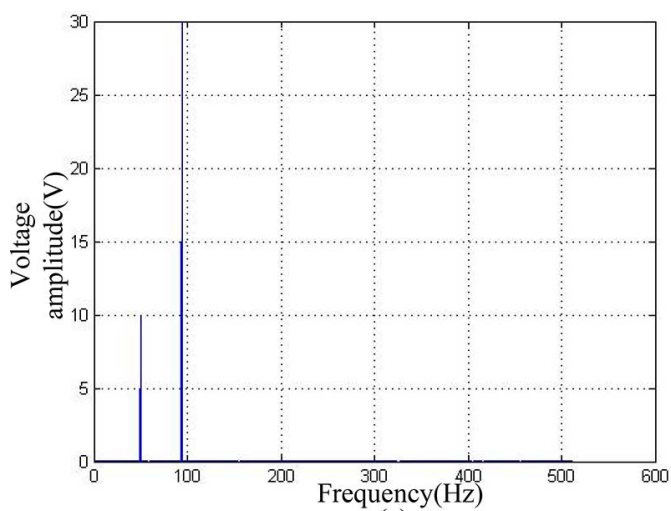

(a)

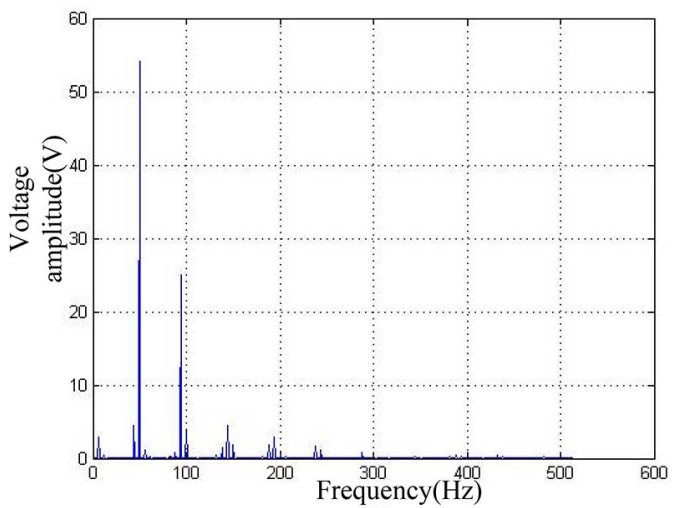

(b)

Fig. 5. Frequency spectrum of two output signals (same input) from ADC after being processed by the FFT: (a) when the signal voltage amplitude $\mathrm{V}_{\mathrm{M} 1}$ is smaller than $V_{R}$ and (b) when the signal voltage amplitude $V_{M 1}$ is greater than $\mathrm{V}_{\mathrm{R}}$.

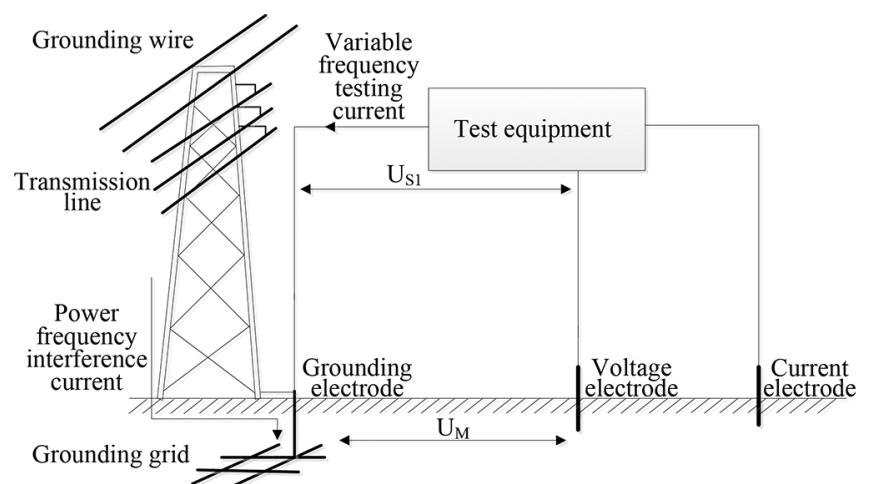

(a)

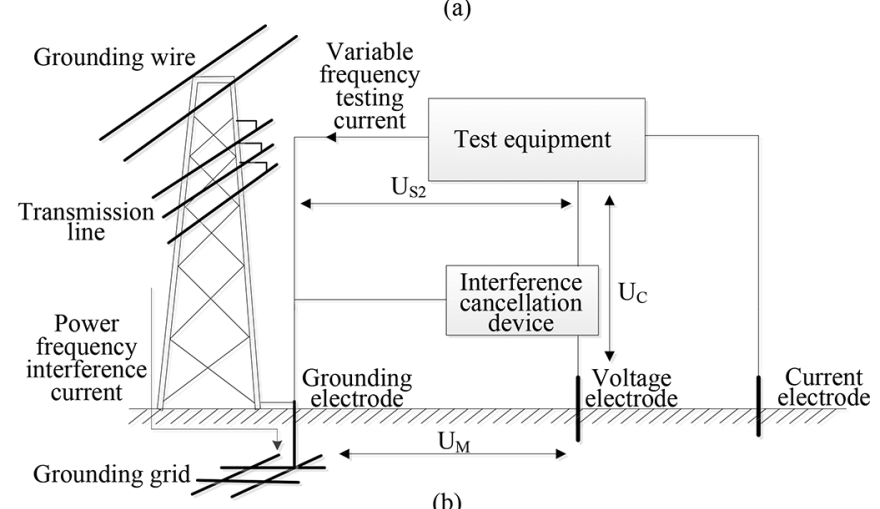

(b)

Fig. 6. Principle of RPC method: (a) schematic diagram of the VF methodbased measurement and (b) RPC method-based measurement with the addition of the interference cancellation device.

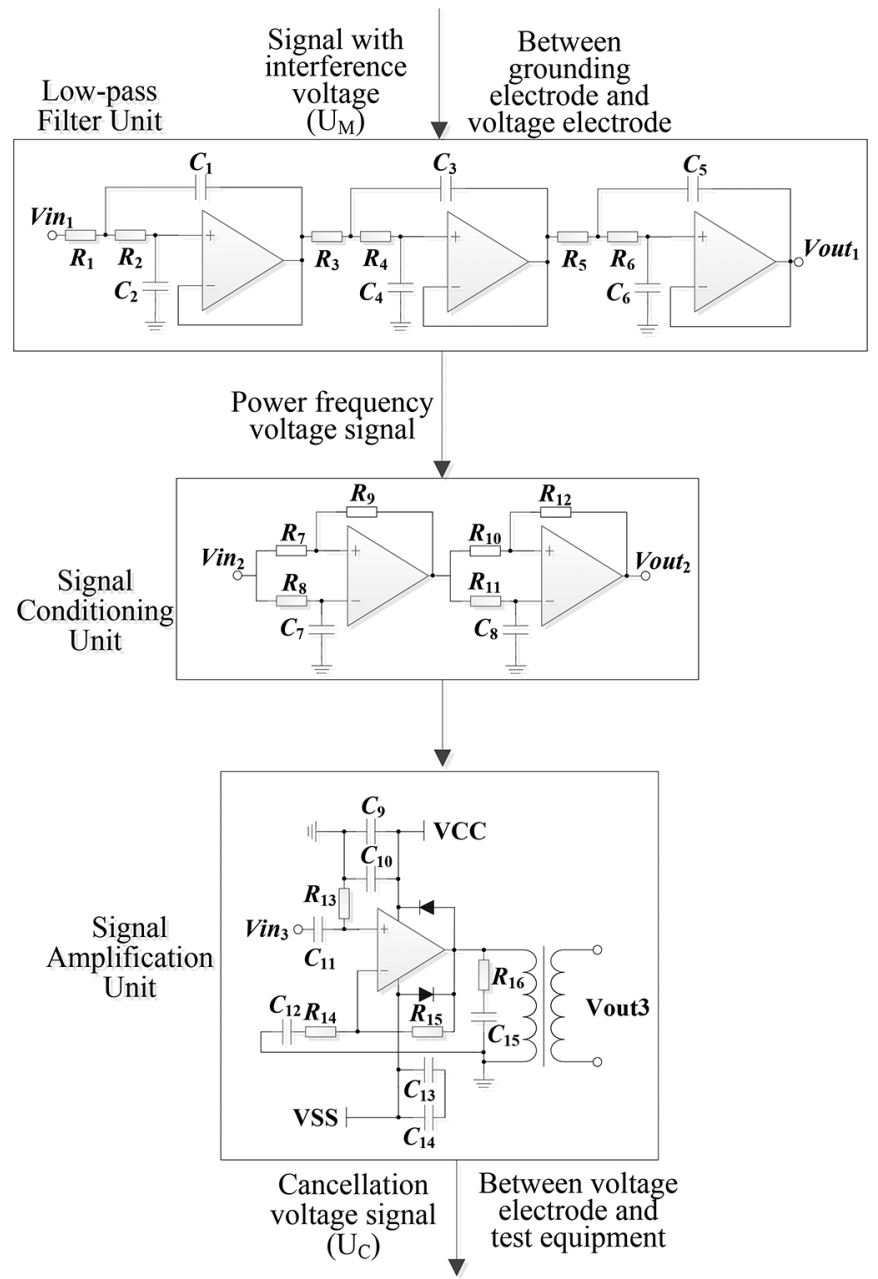

Fig. 7. Operating principle of the interference cancellation device.

frequency interference as (13)-(15) shows. In Fig. 6, $\mathrm{U}_{\mathrm{S} 1}$ and $\mathrm{U}_{\mathrm{S} 2}$ are the voltage signal acquired by the test equipment, $\mathrm{U}_{\mathrm{T}}$ is the variable frequency testing voltage, and $\mathrm{U}_{\mathrm{ST}}$ is the power frequency interference voltage, and $U_{C}$ is the interference cancellation voltage

$$
\begin{aligned}
\dot{U}_{S 1} & =\dot{U}_{M}=\dot{U}_{S T}+\dot{U}_{T} \\
\dot{U}_{C} & =-\dot{U}_{S T} \\
\dot{U}_{S 2} & =\dot{U}_{M}+\dot{U}_{C}=\dot{U}_{T} .
\end{aligned}
$$

\section{B. Design Principle of the Interference Cancellation Device}

Fig. 7 shows the design principle of the interference cancellation device. The input voltage signal $\left(\mathrm{U}_{\mathrm{M}}\right)$ is first acquired between the grounding electrode and the voltage electrode before being passed to the low-pass filter unit. The input voltage signal is then analyzed to make sure that the cancellation voltage signal generated in the system always has the same frequency as the interference voltage signal. Tests showed that when the difference between these two signals is greater than $0.04 \mathrm{~Hz}$, the power frequency interference becomes impossible to eliminate. $\mathrm{U}_{\mathrm{M}}$ contains a voltage signal at power frequency and the test voltage signal generated by the test equipment. The test voltage frequency is automatically selected from a discrete list of values 

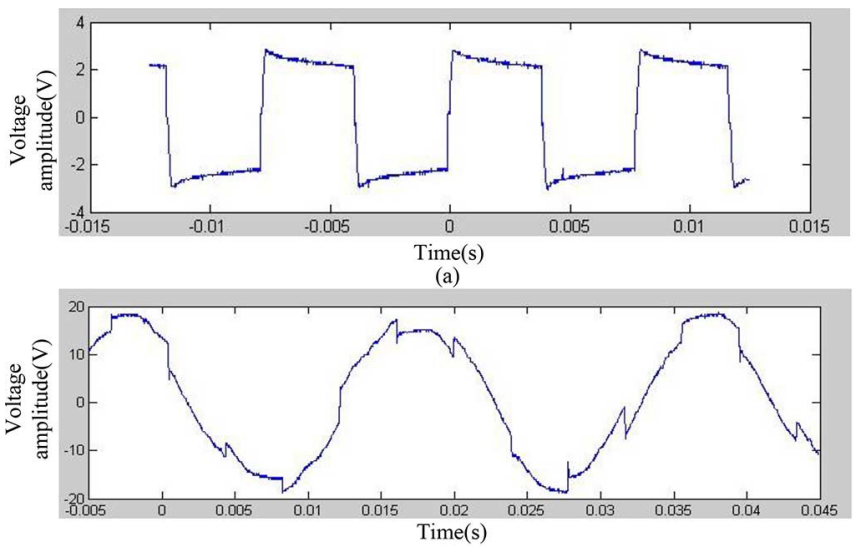

(b)

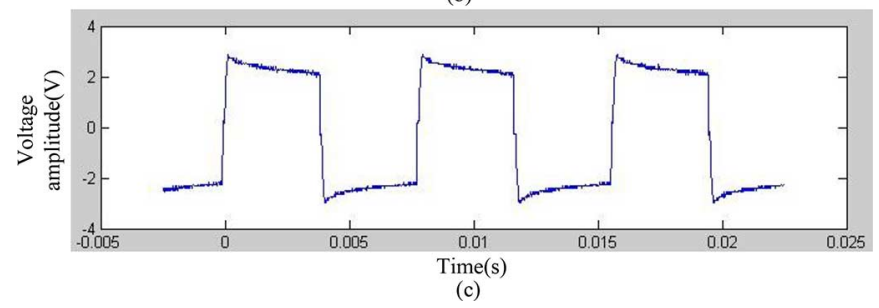

Fig. 8. Voltage signals as measured by the RPC method-based grounding resistance test equipment: (a) the testing voltage signal at the frequency of $128 \mathrm{~Hz}$; (b) the resulting signal containing a signal at power frequency and the testing signal, and (c) the voltage signal measured by grounding resistance test equipment after using the RPC method.

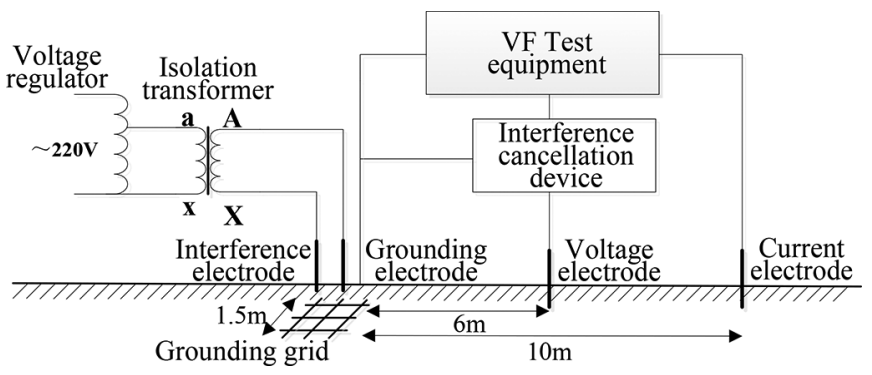

Fig. 9. Schematic diagram of the laboratory test.

(94, 105, 111, and $128 \mathrm{~Hz}$ ) [25]. A low-pass filter that has a cutoff frequency of $128 \mathrm{~Hz}$ is provided to separate the power interference voltage signal and the test voltage signal. An interference cancellation device capable of varying phase and amplitude was designed. The power frequency voltage signal is adjusted by the signal conditioning unit and amplified to generate a cancellation voltage signal $\left(\mathrm{U}_{\mathrm{C}}\right)$.

Fig. 8 shows that with the application of the RPC method for a test frequency of $128 \mathrm{~Hz}$, the power frequency interference voltage can be removed, while the variable frequency testing signal is left intact.

\section{LABORATORY TEST RESULtS}

\section{A. Test Setup and Test Method}

Tests were carried out at the High Voltage Research Institute at Wuhan University. The schematic diagram of the laboratory test is given in Fig. 9. A voltage regulator and an isolation transformer were used to provide an interference
TABLE I

LABORATORY Test MEASURING GROUNDING RESISTANCE

\begin{tabular}{|c|c|c|c|}
\hline $\begin{array}{l}\text { External } \\
\text { disturbance } \\
\text { voltage }(\mathrm{V}) \\
\end{array}$ & $\begin{array}{l}\text { Working } \\
\text { condition }\end{array}$ & $\mathrm{U}_{\mathrm{ST}}(\mathrm{V})$ & $\mathrm{R}_{\mathrm{E}}(\Omega)$ \\
\hline 0 & $\begin{array}{l}\text { Without } \\
\text { RPC } \\
\text { method }\end{array}$ & 0 & $\begin{array}{l}82.4 \\
82.7 \\
82.8 \\
82.5\end{array}$ \\
\hline \multirow{2}{*}{5} & $\begin{array}{l}\text { Without } \\
\text { RPC } \\
\text { method }\end{array}$ & 5 & $\begin{array}{l}82.7 \\
83.1 \\
82.8 \\
82.7\end{array}$ \\
\hline & $\begin{array}{l}\text { With RPC } \\
\text { method }\end{array}$ & 0.8 & $\begin{array}{l}82.7 \\
82.8 \\
82.9 \\
82.7\end{array}$ \\
\hline \multirow{2}{*}{15.4} & $\begin{array}{l}\text { Without } \\
\text { RPC } \\
\text { method }\end{array}$ & 15.4 & $\begin{array}{l}83.6 \\
82.3 \\
83.4 \\
83.4\end{array}$ \\
\hline & $\begin{array}{l}\text { With RPC } \\
\text { method }\end{array}$ & 0.9 & $\begin{array}{l}83.2 \\
83.3 \\
83.3 \\
83.4\end{array}$ \\
\hline \multirow[b]{2}{*}{31} & $\begin{array}{l}\text { Without } \\
\text { RPC } \\
\text { method }\end{array}$ & 31 & $\begin{array}{c}\text { Test equipment is } \\
\text { deactivated }\end{array}$ \\
\hline & $\begin{array}{l}\text { With RPC } \\
\text { method }\end{array}$ & 0.8 & $\begin{array}{l}83.5 \\
83.6 \\
83.4 \\
83.2 \\
\end{array}$ \\
\hline \multirow[b]{2}{*}{48.7} & $\begin{array}{l}\text { Without } \\
\text { RPC } \\
\text { method }\end{array}$ & 48.7 & $\begin{array}{c}\text { Test equipment is } \\
\text { deactivated }\end{array}$ \\
\hline & $\begin{array}{l}\text { With RPC } \\
\text { method }\end{array}$ & 0.7 & $\begin{array}{l}83.5 \\
83.6 \\
83.4 \\
83.8\end{array}$ \\
\hline
\end{tabular}

signal. Grounding resistance test equipment adopting the VF method was purchased and employed to measure the grounding resistance. The test voltages were $48 \mathrm{~V}$ in all tests. The VF method device used in this paper was always deactivated when external interference voltage exceeded $24 \mathrm{~V}$. By adjusting the output of the interference source, the magnitude of the power frequency interference voltage can be changed. The electrodes were spaced as a straight line. The structure of the grounding grid was square compact grid. The side length of the grounding grid was $1.5 \mathrm{~m}$. The grounding electrode is located above the center of the grounding grid. The spacing between the grounding electrode and voltage electrode was $6 \mathrm{~m}$, and the spacing between the grounding electrode and current electrode was $10 \mathrm{~m}$.

\section{B. Test Results}

When the interference cancellation device was connected between the voltage electrode and the test equipment, the interference signal was adjusted to produce the following values: $\mathrm{U}_{\mathrm{ST}}=5 \mathrm{~V}, 15.4 \mathrm{~V}, 31 \mathrm{~V}$, and $48.7 \mathrm{~V}$. In order to ensure the accuracy of test results, each value of $R_{E}$ was measured from separate tests.

Table I gives the results of the laboratory test. The zero interference case is to ensure the consistency of the RPC method. The results show that the RPC method successfully cancels the power frequency interference. 


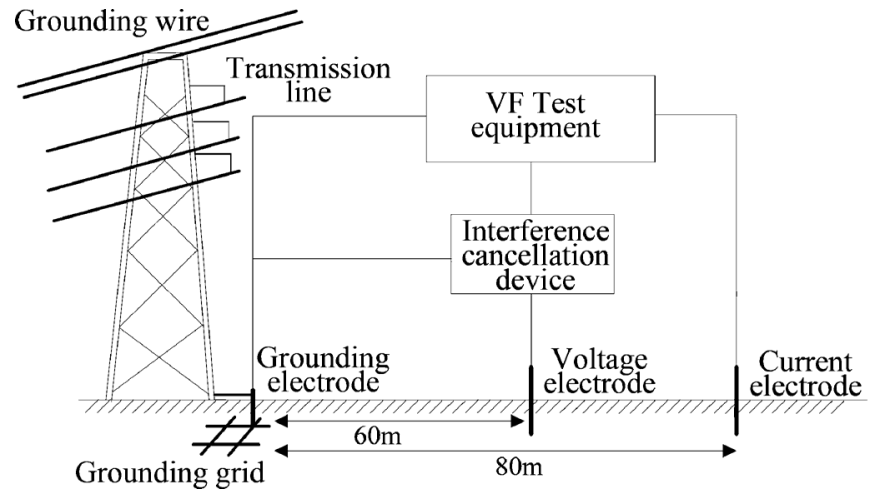

Fig. 10. Schematic diagram of the field test.

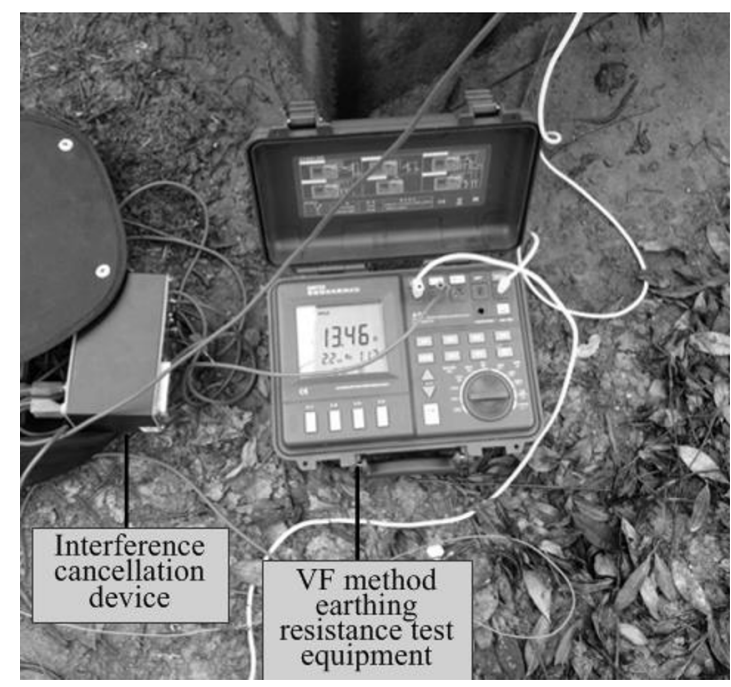

Fig. 11. RPC method in field testing.

\section{Field Test and Test Results}

\section{A. Test Setup and Test Method}

Field tests were performed at four $220-\mathrm{kV}$ transmission towers in a mountainous area in China. Two regular transmission towers and two transposition towers were used, each having two ground wires.

A schematic of the field tests employing the VF method is shown in Fig. 10. The towers were each grounded by means of a radial counterpoise to a different extent, each larger than the compact grounding grid employed in the laboratory tests. The length of all radial counterpoises is about $60 \mathrm{~m}$. The depth of all the radial counterpoises is about $0.8 \mathrm{~m}$. The orientation of the radial counterpoises relative to the test leads and electrodes is parallel. The test electrodes were linearly arranged. The grounding electrode was located in the center of the tower. The spacing between the grounding electrode and the voltage electrode was $60 \mathrm{~m}$, and the distance between the grounding electrode and the current electrode was $80 \mathrm{~m}$ in each field test [26]. The orientation of the test leads relative to the transmission line is perpendicular.

\section{B. Field Test Results}

Fig. 11 shows the picture of field tests under a transmission tower. Tables II and III summarize the test results for the reg-
TABLE II

Grounding Resistance of the Field Test at REGULAR TRANSMISSION TOWER \#1

\begin{tabular}{ccc}
\hline \hline $\begin{array}{c}\text { Working } \\
\text { condition }\end{array}$ & $\mathrm{U}_{\mathrm{ST}}(\mathrm{V})$ & $\mathrm{R}_{\mathrm{E}}(\Omega)$ \\
\hline \multirow{2}{*}{ Without } & & 13.76 \\
RPC & 5.3 & 13.79 \\
method & & 13.74 \\
& & 13.78 \\
\hline \multirow{2}{*}{ With RPC } & & 13.83 \\
method & 0.3 & 13.85 \\
& & 13.87 \\
\hline
\end{tabular}

TABLE III

Grounding Resistance of the Field Test at REGULAR TRANSMISSION TOWER \#2

\begin{tabular}{ccc}
\hline \hline $\begin{array}{c}\text { Working } \\
\text { condition }\end{array}$ & $\mathrm{U}_{\mathrm{ST}}(\mathrm{V})$ & $\mathrm{R}_{\mathrm{E}}(\Omega)$ \\
\hline \multirow{2}{*}{ Without } & & 18.15 \\
RPC & \multirow{2}{*}{10.8} & 18.10 \\
method & & 18.13 \\
& & 18.12 \\
\hline \multirow{3}{*}{ With RPC } & \multirow{2}{*}{0.4} & 18.19 \\
method & & 18.21 \\
& & 18.18 \\
\hline
\end{tabular}

TABLE IV

Grounding Resistance of the Field Test at THE PHASE-WIRE TRANSPOSITION TOWER \#1

\begin{tabular}{ccc}
\hline \hline $\begin{array}{c}\text { Working } \\
\text { condition }\end{array}$ & $\mathrm{U}_{\mathrm{ST}}(\mathrm{V})$ & $\mathrm{R}_{\mathrm{E}}(\Omega)$ \\
\hline $\begin{array}{c}\text { Without } \\
\text { RPC }\end{array}$ & 25.3 & $\begin{array}{c}\text { Test equipment is } \\
\text { deactivated }\end{array}$ \\
method & & 13.51 \\
With RPC & & 13.48 \\
method & 0.8 & 13.46 \\
& & 13.47 \\
\hline
\end{tabular}

TABLE V

Grounding Resistance of the Field Test at PHASE-WIRE TRANSPOSITION TOWER \#2

\begin{tabular}{ccc}
\hline \hline $\begin{array}{c}\text { Working } \\
\text { condition }\end{array}$ & $\mathrm{U}_{\mathrm{ST}}(\mathrm{V})$ & $\mathrm{R}_{\mathrm{E}}(\Omega)$ \\
\hline $\begin{array}{c}\text { Without } \\
\text { RPC } \\
\text { method }\end{array}$ & 33.6 & $\begin{array}{c}\text { Test equipment is } \\
\text { deactivated }\end{array}$ \\
\hline With RPC & & 17.83 \\
method & 0.8 & 17.88 \\
& & 17.82 \\
& & 17.84 \\
\hline
\end{tabular}

ular transmission towers. Results of the phase-wire transposition tower tests are given in Tables IV and V. The results show that the RPC method is capable of cancelling the power frequency interference in the field test, and can enable the VF grounding resistance test equipment to work normally when in conditions of strong interference. The measurement error is less 
than $1 \%$ with the addition of the RPC device when the interference is below the threshold value. The results also show that the current flowing into the ground from the tower is greater when transmission conductors are transposed.

\section{DISCUSSION}

The RPC method has the following improvement by comparing with the interference compensation (IC) method proposed by IEEE standard 81-2 [27].

The signal-to-noise ratio (SNR) of the RPC method is about $36 \mathrm{~dB}\left(\mathrm{SNR}_{\mathrm{RPC}}=20 \lg \left(V_{\mathrm{S}} / V_{\mathrm{N}}\right)=20 \lg (50 / 0.8) \approx 36 \mathrm{~dB}\right)$. A comparison of field and laboratory test results show that the measurement error introduced by the RPC equipment is in all cases less than $1 \%$. The results also demonstrate that the interference cancellation device operates effectively with different sizes and types of the grounding grid.

The IC method also requires a three-phase ac source, with the compensation voltage signal being manually controlled. The battery-powered RPC equipment has the advantage of portability, and automatic generation of the compensation voltage signal improves ease of use.

\section{CONCLUSION}

When attempting to measure the grounding resistance of an HV transmission tower situated in a mountainous area, the power frequency interference voltage often becomes so excessively high that the VF method would not function. This paper has analyzed the sources and mechanism of power frequency interference during the measurement of transmission tower ground resistance. Theoretical analysis has shown that induced current flowing into the ground is responsible for the interference. The interference voltage may be further increased in the presence of great grounding resistance.

This paper has proposed a reverse-phase cancellation method as a means of mitigating the effect of power frequency interference. The proposed RPC method effectively removes the power frequency interference voltage, and enables measurement of the grounding resistance normally and accurately using VF method grounding resistance test equipment, even in the presence of strong interference.

\section{REFERENCES}

[1] J. He, R. Zeng, Y. Tu, J. Zou, S. Chen, and Z. Guan, "Laboratory investigation of impulse characteristics of transmission tower grounding devices," IEEE Trans. Power Del., vol. 18, no. 3, pp. 994-1001, Jul. 2003.

[2] S. Furukawa, O. Usuda, T. Isozaki, and T. Irie, "Development and applications of lightning arresters for transmission lines," IEEE Trans. Power Del., vol. 4, no. 4, pp. 2121-2129, Oct. 1989.

[3] A. Ametani and T. Kawamura, "A method of a lightning surge analysis recommended in Japan using EMTP," IEEE Trans. Power Del., vol. 20, no. 2, pt. 1, pp. 867-875, Apr. 2005.

[4] I. M. Dudurych, T. J. Gallagher, J. Corbett, and M. V. Escudero, "EMTP analysis of the lightning performance of a HV transmission line," in Proc. Inst. Elect. Eng., Gen., Transm. Distrib., 2003, vol. 150, no. 4, IET.

[5] H. Shu et al., "Lightning withstand level calculation and anti-lightning method research for transmission lines across heavily icing region," presented at the IEEE Power Energy Eng. Conf, Asia-Pacific. Chengdu, China, 2010.
[6] J. Ma and F. P. Dawalibi, "Extended analysis of ground impedance measurement using the fall-of-potential method," IEEE Trans. Power Del., vol. 17, no. 4, pp. 881-885, Oct. 2002.

[7] N. Izumo, S. Takagi, and Y. Kishimoto et al., "A new method of measuring ground resistance applicable to mutually bonded grounding electrode systems," presented at the IEEE 21st Int. Telecommun. Energy Conf., Copenhagen, Denmark, 1999.

[8] C.-G. Wang, T. Takashima, and T. Sakuta et al., "Grounding resistance measurement using fall-of-potential method with potential probe located in opposite direction to the current probe," IEEE Trans. Power Del., vol. 13, no. 4, pp. 1128-1135, Oct. 1998.

[9] P. R. Pillai and E. P. Dick, "A review on testing and evaluating substation grounding systems," IEEE Trans. Power Del., vol. 7, no. 1, pp. 53-61, Jan. 1992.

[10] F. P. Zupa and J. F. Laidig, "A practical ground potential rise prediction technique for power stations," IEEE Trans. Power App. Syst., vol. PAS-99, no. 1, pp. 207-216, Jan. 1980.

[11] M. I. Lorentzou, N. D. Hatziargyriou, and B. C. Papadias, "Time domain analysis of grounding electrodes impulse response," IEEE Trans. Power Del., vol. 18, no. 2, pp. 517-524, Apr. 2003.

[12] C. Xiaokuo and L. Yanming, "Study of EHV power grid over-voltage monitoring system based on Rogow ski coil," in Proc. IEEE 4th Int. Conf.. Elect. Utility Dereg. Restruct. Power Technol., 2011, pp. 1741-1746.

[13] A. Soares, Jr., M. A. O. Schroeder, and S. Visacro, "Transient voltages in transmission lines caused by direct lightning strikes," IEEE Trans. Power Del., vol. 20, no. 2, pt. 2, pp. 1447-1452, Apr. 2005.

[14] L. M. Popovic, "Practical method for evaluating ground fault current distribution in station, towers and grounding wire," IEEE Trans. Power Del., vol. 13, no. 1, pp. 123-128, Jan. 1998.

[15] F. Dawalibi and G. B. Niles, "Measurements and computations of fault current distribution on overhead transmission lines," IEEE Trans. Power App. Syst., vol. PAS-103, no. 3, pp. 553-560, Mar. 1984.

[16] T. D. Bracken, "Field measurements and calculations of electrostatic effects of overhead transmission lines," IEEE Trans. Power App. Syst., vol. PAS-95, no. 2, pt. 1, pp. 494-504, Mar. 1976.

[17] L. M. Wedepohl and D. J. Wilcox, "Transient analysis of underground power-transmission systems. System-model and wave-propagation characteristics," in Proc. Inst. Elect. Eng., Feb. 1973, vol. 120, no. 2, pp. 253-260.

[18] A. J. F. Keri, A. Nourai, and J. M. Schneider, "The open loop scheme: An effective method of grounding wire loss reduction," IEEE Trans. Power App. Syst., vol. PAS-103, no. 12, pp. 3615-3624, Dec. 1984.

[19] K. Nakada, T. Yokota, S. Yokoyama, A. Asakawa, M. Nakamura, H. Taniguchi, and A. Hashimoto, "Energy absorption of surge arresters on power distribution lines due to direct lightning strokes-effects of an overhead ground wire and installation position of surge arresters," IEEE Trans. Power Del., vol. 12, no. 4, pp. 1779-1785, Oct.. 1997.

[20] M. Komoda and K. Sasaki, "Method of reducing power loss in ground wire of overhead transmission lines[J]," Elect. Eng. Jpn., vol. 111, no. 3, pp. 18-28, 1991

[21] Grounding and Protection Against Electric Shock, IEC 60050-195, 1998.

[22] P. H. Reynolds and D. S. Ironside, "A new instrument for measuring ground impedances," in Proc. IEEE Power Eng. Soc. Winter Meeting, New York, 1979, vol. 79, pp. 134-137.

[23] H. Griffiths, P. Jones, N. Harid, and A. Haddad, "Proposal for measurement of earth impedance using variable frequency injection," Meas. Sci. Technol., vol. 21, no. 8, p. 085102, 2010.

[24] B. Le, T. W. Rondeau, J. H. Reed, and C. W. Bostian, "Analog-to-digital converters," IEEE Signal Process. Mag., vol. 22, no. 6, pp. 69-77, Nov. 2005.

[25] L. Li, J. Zou, and H. Sun, "Research on the new clamp-on ground resistance on-line tester based on AC variable frequency," in Proc. IEEE 6th World Congr. Intell. Control Autom., 2006, vol. 2, pp. 5286-5289.

[26] IEEE Guide for Measuring Earth Resistivity, Ground Impedance, and Earth Surface Potentials of a Grounding System, IEEE Standard 81-2012.

[27] IEEE Guide for Measurement of Impedance and Safety Characteristics of Large, Extended or Interconnected Grounding Systems, IEEE Standard 81.2-1991. 


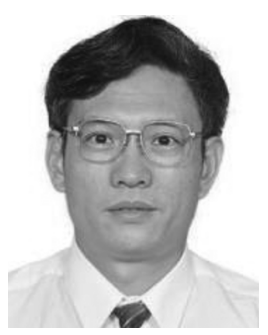

Wenjun Zhou (SM'13) was born in China on July 1, 1959. He received the Ph.D. degree in high-voltage engineering from Wuhan University of Hydraulic and Electrical Engineering, Wuhan, China, in 1990.

Currently, he is a Professor in the School of Electrical Engineering, Wuhan University. He is a member of the High Voltage Committee of the Chinese Society of Electrical Engineering (CSEE), the Electro-technical Test and Measurement Committee of the China Electrotechnical Society (CES), and the China Lightning Protection Standard Committee. He is also the Vice Director of the Hubei High Voltage Committee. His research interests include lightning protection and the diagnostic techniques for outdoor electrical insulation.

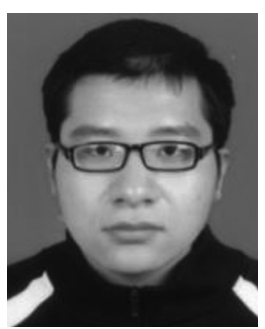

Yushun Liu was born in Chaohu, Anhui Province, China, in 1990. He received the B.Sc. degree in electrical engineering from the School of Electrical Engineering, Shaanxi University of Technology, Hanzhong, China, in 2012 and is currently pursuing the Ph.D. degree in electrical engineering at Wuhan University, Wuhan, China.

His research is mainly focused on high-voltage techniques.

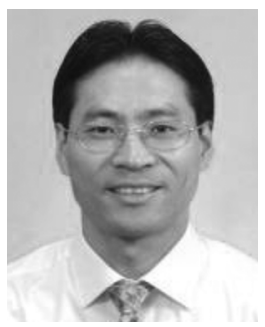

Gongxin Li was born in Fuzhou, Fujian Province, China, in 1964. He received the B.Sc. degree in electrical engineering at the School of Zhejiang University, Hangzhou, China, in 1984 and is currently pursuing the $\mathrm{Ph} . \mathrm{D}$. degree in electrical engineering at Wuhan University, Wuhan, China.

Currently, he is a Senior Engineer with Fujian Electric Power Co. Ltd., Fuzhou, China. His research is mainly focused on high-voltage techniques.

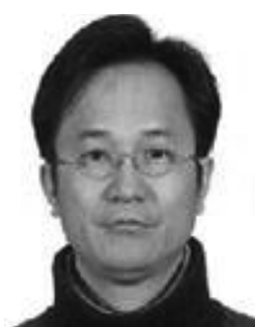

Guozhi Yan was born in Ezhou, Hubei Province, China, in 1963. He received the Ph.D. degree in electrical engineering from Wuhan University, Wuhan, China, in 1993.

Currently, he is an Associate Professor at the School of Electrical Engineering, Wuhan University. His research mainly focuses on measuring and testing techniques.

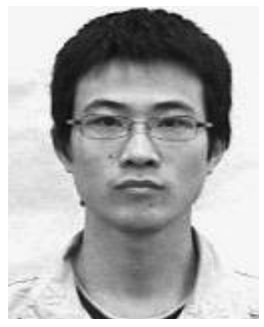

Shuai Yang was born in China on October 20, 1987. $\mathrm{He}$ received the Ph.D. degree in high-voltage engineering from Wuhan University of Electrical Engineering and Automation, Wuhan, China.

Currently, he is a Postdoctor at the School of Electrical Engineering of Wuhan University, Wuhan. His research mainly focuses on high voltage and electrical insulation.

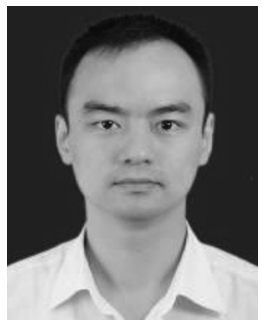

Han Li was born in Wuhan, Hubei Province, China, in 1980. He received the B.Sc. degree in electrical engineering from Wuhan University, Wuhan, China in 2002, the M.Sc. degree in high-voltage engineering from South China University of Technology, Guangzhou, China, in 2006, and the Ph.D. degree in electrical engineering from Wuhan University in 2011.

His research mainly focuses on high voltage and electrical insulation.

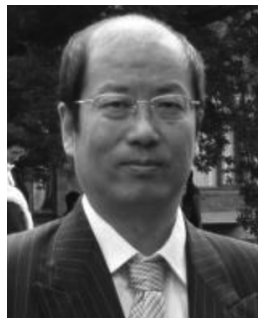

Chengke Zhou (SM'13) received the B.Sc. and M.Sc. degrees in electrical engineering from the Huazhong University of Science and Technology, Wuhan, China, in 1983 and 1986, respectively, and the Ph.D. degree in high-voltage engineering from the University of Manchester, Manchester, U.K., in 1994

He joined the School of Engineering and Computing, Glasgow Caledonian University (GCU), Glasgow, U.K., in 1994 and became a Postdoctoral Research Fellow, Lecturer, and Senior Lecturer until 2006, when he joined Heriot-Watt University, Edinburgh, Scotland, U.K., as a Reader. In 2007, he returned to GCU as a Professor. He has more than 30 years research experience in power systems and partial discharge-based high-voltage plant condition monitoring and has acted as a Consultant to EDF Energy, Scottish Power plc., and British Energy, Edinburgh. So far, he has bpublished more than 100 papers.

Dr. Zhou is also a Fellow of IET and a Chartered Engineer.

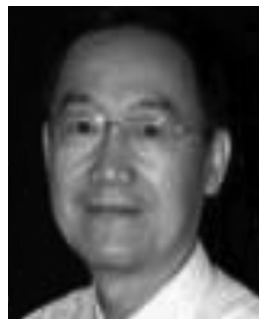

models.
Charles Qi Su (SM'91) received the M.Eng. degree in electrical engineering from Wuhan University of Hydraulic and Electric Engineering, Wuhan, China, in 1981, and the Ph.D. degree in high-voltage engineering from the University of New South Wales (UNSW), Sydney, Australia, in 1990.

Currently, he is a Guest Professor at Wuhan University, Wuhan, China. His main research interests include insulation condition monitoring, reliabilitycentered maintenance, fuzzy diagnosis of electrical plant and transformers, and generator high-frequency

Dr. Su has been a Fellow of IET since 1991. 